\title{
Dimensões e tendências da economia solidária no Brasil
}

Recebido: 25.05.18 Aprovado: 16.05 .19

\author{
Luiz Inácio Gaiger* \\ \& Patrícia Kuyven**
}

Resumo: O artigo realça o valor do Sistema de Informações em Economia Solidária para a compreensão da economia solidária no país, destacando suas possibilidades investigativas no sentido de apurar aspectos relevantes dos empreendimentos de economia solidária (EES) e identificar suas origens e tendências de desenvolvimento. Salienta as peculiaridades da economia solidária diante das formas predominantes de economia e apresenta uma tipologia dos EES, integrando-a à análise de seu processo de emergência, no qual se destaca o lastro de experiências dos trabalhadores. Essa discussão conduz a examinar o sentido da economia solidária do ponto de vista das expectativas de seus protagonistas e a relativizar teses correntes como aquela de uma reação ao desemprego ou de mera busca de benefícios econômicos. Tece comentários sobre a importância de bases de dados abrangentes para os estudos sobre a economia solidária, no sentido de estabelecer balanços sobre sua trajetória e suas forças de propulsão, finalizam o artigo.

Palavras-chave: Economia solidária. Economia popular. Informalidade. Cooperativas. Sistema de Informações em Economia Solidária (Sies).

\section{Dimensions and trends of the solidarity economy in Brazil}

Abstract: The paper highlights the value of the Brazilian Information System on Solidarity Economy for the understanding of solidarity economy, highlighting its investigative possibilities in order to ascertain relevant aspects of Solidarity Economy Enterprises (EES) and to identify their origins and development tendencies. It emphasizes the peculiarities of the solidarity economy in the face of the predominant forms of economy and presents an EES' typology, integrating it to the analysis of its emergent process, in which the workers' experiences are highlighted. This discussion leads to the exam of the sense of solidarity economy from the point of view of the expectations of its protagonists, and to relativize current theses such as a reaction to unemployment or the mere pursuit of economic benefits. Comments on the importance of comprehensive databases for studies on solidarity economy, in order to establish balance sheets on their trajectory and their propulsion forces, conclude the paper.

Keywords: Solidarity economy - popular economy - informality - cooperatives-Solidarity Economy Information System (Sies)

\author{
* Luiz Inácio Gaiger \\ é doutor em \\ sociologia e docente \\ do Programa de \\ Pós-graduação em \\ Ciências Sociais \\ da Universidade \\ do Vale do Rio dos \\ Sinos (Unisinos), \\ São Leopoldo, Rio \\ Grande do Sul, \\ Brasil. \\ Orcid :0000-0003- \\ 0241-7064. \\ <gaiger@unisinos. \\ br>. \\ ** Patrícia Kuyven \\ é doutora em \\ ciências sociais na \\ Universidade do \\ Vale do Rio dos \\ Sinos (Unisinos), \\ professora adjunta \\ da Unisinos, São \\ Leopoldo, Rio \\ Grande do Sul, \\ Brasil. \\ Orcid: 0000-0001- \\ 5938-8829. E-mail: \\ <pkuyven@unisinos. \\ $b r>$.
}




\section{Introdução}

1. Conforme a

Pesquisa Nacional de Amostras por Domicílio de 2013 e o Censo do IBGE de 2010. Informações em: <https:// ww2.ibge.gov.br/ home/estatistica/ populacao/trabalhoe rendimento/ pnad2013/default. shtm (PNAD)> e em <https:// ww2.ibge.gov.br/ home/estatistica/ populacao/ censo2010/default. shtm $>$ (Censo Demográfico).

2. Instância com representações do Estado, do Fórum Brasileiro de Economia Solidária e de entidades de apoio e fomento.
O Instituto Brasileiro de Geografia e Estatística (IBGE) estimou em 2013 que a população brasileira já ultrapassara a casa dos 200 milhões de habitantes ${ }^{1}$. No mesmo ano, o segundo Mapeamento Nacional da Economia Solidária no Brasil contabilizou cerca de 1,4 milhão de pessoas integrantes dos empreendimentos econômicos solidários (EES), na condição de trabalhadores, consumidores ou usuários de seus bens e serviços. Que relações poderiam ser estabelecidas entre um universo e outro? Comparações desse tipo, por certo, requerem que se possa antes aquilatar a participação demográfica, social e econômica da economia solidária, o que não era possível até anos atrás, por inexistirem dados estatísticos abrangentes a esse respeito.

Em 2003, essa situação começou a mudar com a criação da Secretaria Nacional de Economia Solidária (Senaes). Em conjunto com o Fórum Brasileiro de Economia Solidária (FBES), a secretaria decidiu-se por um amplo mapeamento da economia solidária no Brasil, realizado entre 2005 e 2007, com o qual cerca de 22 mil EES foram identificados e caracterizados. O mapeamento deu origem ao Sistema de Informações em Economia Solidária (Sies), propiciando o acesso público aos dados e prevendo sua atualização periódica, de acordo com diretrizes emanadas do Conselho Nacional de Economia Solidária e com resoluções da Comissão Gestora Nacional² do Sies. Entre 2010 e 2013 foi realizado um segundo mapeamento nacional; em 2013, os dados do segundo mapeamento serviram de base a uma pesquisa amostral, adiante descrita.

A efetivação do Sies supôs um acordo prévio em relação às características definidoras das unidades de coleta de informações, os EES. Para serem mapeados, os empreendimentos deveriam ser organizações suprafamiliares, com ao menos dois associados, e atuação econômica permanente, sob a forma de associações, cooperativas, empresas autogestionárias, grupos de produção, clubes de troca etc., cujos participantes realizassem coletivamente a gestão das atividades e decidissem sobre a alocação dos seus resultados. Sua inclusão no mapeamento não requereria que tivessem registro legal ou algum tipo de formalização, mas sim que desenvolvessem atividades de produção de bens, prestação de serviços, comercialização, consumo ou crédito. O primeiro mapeamento abrangeu organizações complexas (ou de segundo grau), principalmente redes e centrais cooperativas, ao passo que o segundo mapeamento se restringiu às organizações de primeiro grau, registrando ao mesmo tempo suas eventuais vinculações externas.

O trabalho inédito de coleta de dados que originou o Sies tornou-se possível graças à liderança da Senaes e à colaboração de inúmeros órgãos públicos e enti- 
dades de apoio à economia solidária, além das diversas redes e fóruns que se instituíram nas duas últimas décadas, convergindo em seus propósitos e linhas de atuação. Foi igualmente decisivo o suporte de universidades e instituições de pesquisa, como o Instituto de Pesquisa Econômica Aplicada (Ipea) e o Departamento Intersindical de Estatísticas e Estudos Socioeconômicos (Dieese) ${ }^{3}$. Contudo, salvo um livro dedicado à análise dos dados mais salientes do segundo mapeamento (Gaiger et alii, 2014) e alguns estudos esparsos, as bases de informação do Sies permanecem pouco exploradas e, no geral, ainda distantes do olhar e da compreensão de acadêmicos, agentes públicos e ativistas da economia solidária.

O Sies não contém apenas os grandes números da economia solidária, mas um conjunto de informações que permite correlacionar as características dos EES, traçar modelos e, ademais, identificar as tendências que deram origem a essas iniciativas e que definem suas dinâmicas de atuação e evolução. Embora os últimos levantamentos de informações tenham sido concluídos em 2013, guardam interesse na atualidade ao facultarem análises retrospectivas da gênese dos EES, considerando tanto fatores endógenos próprios desse campo de práticas quanto o efeito de circunstâncias conjunturais. Isso permitiria ultrapassar uma visão de curto prazo e delinear hipóteses adequadamente fundamentadas sobre o curso da economia solidária dos últimos anos, tendo-se em vista as reviravoltas no quadro político nacional e o retraimento das políticas públicas, em particular no âmbito federal, em face da destituição do tema na agenda governamental (Silva, 2018).

A conveniência de um olhar global e de longo prazo sobre a economia solidária já foi enfatizada em trabalhos de pesquisa (Gaiger \& Corrêa, 2010) e balanços do estado da arte (Gaiger, 2012; 2014). Fazê-lo, examinando dados do Sies, traz à luz características dos EES que refinam visões comuns a respeito, como buscaremos demonstrar. Ademais, apura nossa percepção sobre o sentido e o futuro desse campo de práticas, afastando visões estanques em termos ou de mera funcionalidade, ou de plena alternatividade da economia solidária diante da lógica dominante de mercantilização e acumulação capitalista.

O artigo realça o valor do Sies como esforço de apreensão da economia solidária no país e expõe alguns dos principais resultados obtidos, ainda pouco conhecidos e utilizados pelos estudos na área. Primeiramente, apresenta algumas características gerais dos EES, além de traços específicos, com o objetivo de destacar peculiaridades da economia solidária diante das formas predominantes de economia. Algumas distinções serão feitas a esse respeito entre associações, cooperativas e grupos informais. A proposição de uma tipologia dos EES servirá a seguir de base para uma análise do processo de emergência desses empreendimentos, considerando o lastro de experiências dos trabalhadores envolvidos nessas iniciativas,
3. Através do

Observatório

Nacional de

Economia Solidária

e do Cooperativismo

(http://ecosol.

dieese.org.br/),

o Dieese propicia

acesso aos

principais dados dos mapeamentos e tem promovido estudos a respeito. $\mathrm{O}$ acesso aos microdados do Sies - concebidos como uma base de informações de caráter público pode ser requerido ao governo: <http:// trabalho.gov. br/trabalhadoreconomia-solidaria/ programas-e-acoes/ informacoes>. 
bem como os efeitos mais imediatos das transformações econômicas no momento de expansão mais acentuada da economia solidária. A discussão desses fatores nos conduzirá ao exame do sentido da economia solidária do ponto de vista das expectativas de seus protagonistas, questionando-se teses correntes como aquela de uma reação ao desemprego ou de busca de benefícios econômicos. O artigo se encerra com alguns comentários sobre o valor de bases de dados abrangentes para os estudos sobre a economia solidária, como via para a implantação de balanços fundamentados sobre sua trajetória e suas forças de propulsão.

\section{Caracterização geral dos empreendimentos econômicos solidários}

4. A elaboração do questionário tomou como referências as principais pesquisas de base nacional no Brasil, tais como a Economia Informal Urbana (Ecinf), a Pesquisa de Orçamentos Familiares (POF) e a Pesquisa Nacional de Amostra por Domicílios (Pnad). Tais procedimentos encontram-se descritos no site do Projeto Sies, em cujo âmbito realizouse o tratamento e a análise das informações relacionadas ao segundo mapeamento e executou-se a pesquisa amostral (Ver: <http://sies. ecosol.org.br/> e seu detalhamento em Gaiger et alii, 2014).

5. Os percentuais foram arredondados para a primeira casa antes da vírgula, exceto para os valores inferiores a $10 \%$ ou quando a fração posterior à vírgula equivale a $0,5 \%$.
O Sies foi concebido como base para estudos e instrumento para o planejamento das políticas públicas, a partir do reconhecimento e dimensionamento de uma realidade até então não percebida pelos levantamentos oficiais no Brasil. Além das informações a respeito dos EES - constantes do primeiro mapeamento e ampliadas no segundo -, percebeu-se a necessidade de reunir informações sobre as pessoas associadas aos EES, em particular sobre as motivações de sua atuação na economia solidária e sobre os impactos decorrentes. Adicionalmente aos mapeamentos, em 2013 foi realizada uma pesquisa nacional por amostragem, focalizando associadas/os dos EES, com o objetivo de levantar seu perfil e avaliar as principais mudanças provocadas por sua participação nos EES e por seu ativismo na economia solidária e movimentos afins ${ }^{4}$. Assim, o Sies contém informações coletadas em 2005-2007 sobre cerca de 22 mil EES (primeiro mapeamento), informações de 2010-2013 sobre quase 20 mil EES (segundo mapeamento) e informações provenientes da pesquisa amostral sobre os integrantes dos EES. Os dados do período 2010-2013, cujas cifras globais mais importantes figuram no Mapa 1 , nos servirão como principal referência.

A visão mais habitual da economia solidária provavelmente evoca pequenos empreendimentos urbanos, nas franjas do desemprego e da informalidade, nos quais se produzem ou se vendem coletivamente bens de consumo em segmentos de atividades tradicionais tais como alimentação, vestuário e artesanato, por vezes incorporando a oferta de itens ou de atividades com propósitos alternativos e sustentáveis, a exemplo das associações de reciclagem e das feiras ecológicas. Essas últimas concentram produtores e agricultores familiares, quase sempre organizados em cooperativas e associações localizadas em áreas rurais próximas ao perímetro urbano, o que explica que $10 \%$ dos EES registrados no segundo mapeamento tenham declarado atuar no espaço rural e urbano, simultaneamente ${ }^{5}$. No cômputo geral, a área rural prevalece com 55\% dos EES, enquanto os EES urbanos 
MAPA 1

DISTRIBUIÇÃO NACIONAL DOS empreendimentos econômicos solidários E SÓcIOS POR REGIÃO

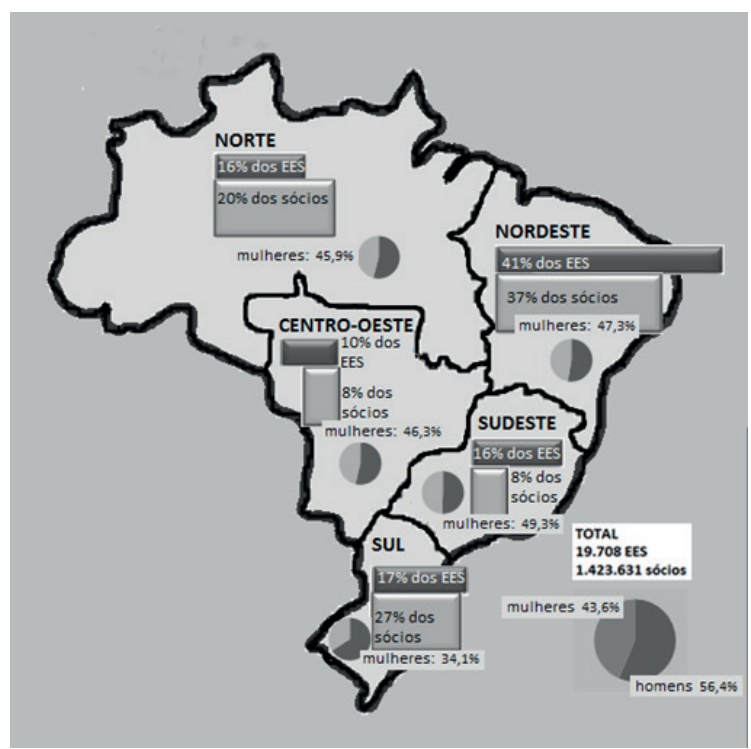

Fonte: Mapeamento Nacional da Economia Solidária.

perfazem 35\%. Deve-se ainda destacar a predominância de ocupações tipicamente agrícolas entre os integrantes dos EES (60\%), denotando que a economia solidária abarca uma fisionomia prevalentemente rural, com base na produção familiar e em seus vínculos típicos de mutualidade e cooperação, cujas raízes recuam e se prolongam no tempo. A economia solidária não é, portanto, um fenômeno tipicamente urbano e tão recente quanto se possa pensar.

A diferença entre os espaços rural e urbano como área de atuação, de exatos 20\%, é fato relacionado à forma de organização dos EES. Associações são a modalidade típica dos EES rurais, integrados por agricultores familiares que se consorciam para utilizar equipamentos e recursos produtivos de forma coletiva, o que aumenta seu poder de barganha diante de fornecedores e otimiza a comercialização dos produtos. Predominam em meio rural (70\%), enquanto nas aglomerações urbanas concentram-se os grupos informais (59\%). As cooperativas ficam divididas, com presença ligeiramente maior no espaço urbano (46\% versus $34 \%)^{6}$.

Essas correlações também incidem sobre a principal atividade econômica coletiva dos $\mathrm{EES}^{7}$. Nesse quesito, observa-se um predomínio (56\%) de EES dedicados prioritariamente à produção de bens (atividade que usualmente envolve a comercia-
6. A magnitude rural da economia solidária justifica a fundação da União Nacional das Cooperativas de Agricultura Familiar e Economia Solidária (Unicafes) em 2005; já os EES urbanos encontramse representados pela Central de Cooperativas e Empreendimentos Solidários (Unisol), criada em 2000.

\section{Após terem} enumerado as diversas atividades econômicas que realizavam coletivamente, os EES indicaram qual delas era a principal, entre seis alternativas:

1. Troca de produtos ou serviços

(incluem-se aqui os EES que utilizam moedas sociais para mediar as trocas);

2. Produção e comercialização (atividades de processamento, beneficiamento, coleta ou fabrico de produtos, com sua respectiva comercialização);

3. Comercialização (realizam

principalmente a comercialização de produtos ou serviços dos sócios ou de terceiros, originados fora do EES);

4. Prestação de serviços ou de trabalho a terceiros (isto é, para não sócios, sejam eles clientes individuais, famílias, empresas, órgãos públicos etc.): 5. Poupança, crédito ou finanças 
solidárias (incluindo cooperativas de crédito, fundos rotativos e bancos comunitários.); 6. Consumo ou uso coletivo de bens e serviços pelos sócios (a exemplo das cooperativas de consumo, habitacionais ou de eletrificação).

8. Os últimos dois tipos são minoritários: a troca de produtos e serviços $(2,2 \%)$ e a atividade de poupança, crédito ou finanças solidárias (1,7\%).

\section{Por ser uma} questão relacionada com renda, ela foi aplicada exclusivamente a três daqueles seis tipos de atividade econômica principal: produção, comercialização e prestação de serviços ou trabalho a terceiros. lização). Bem abaixo desse percentual, estão os EES dedicados ao consumo ou ao uso coletivo de bens e serviços pelos sócios (20\%). Seguem os EES tipicamente de comercialização (13\%) e aqueles de prestação de serviço ou trabalho a terceiros $(6,6 \%)^{8}$. As atividades de consumo e uso coletivo de bens e serviços concentram-se fortemente (85\%) no espaço rural, bem como a troca de produtos e serviços e as atividades de poupança, crédito ou finanças solidárias. No espaço urbano, predominam os EES de prestação de serviços ou de trabalho a terceiros (64\%) e as atividades de comercialização, embora também se realizem no espaço rural. A atividade de produção divide-se com equilíbrio entre os espaços rural e urbano. Por sua vez, as atividades realizadas simultaneamente em área urbana e rural são, principalmente, as de finanças solidárias, de prestação de serviços (ou trabalho) a terceiros e de comercialização. Esses fatos e números dão a correta impressão de que a economia solidária não se distancia das atividades econômicas habituais, menos ainda revoluciona a matriz produtiva das regiões em que os EES se inserem. Seus efeitos e suas inovações são mais sutis, como veremos adiante.

A principal atividade econômica dos EES também se relaciona com a forma de organização que adotam. A atividade de produção, predominante no conjunto de EES, é uma característica ainda mais acentuada nos grupos informais (perfazendo $70 \%$ desse segmento). Já a atividade de consumo ou uso coletivo de bens e serviços é mais frequente nas associações (ocupando 29\% delas). A comercialização se distribui de modo mais homogêneo, com certo destaque entre as cooperativas (27\%). A atividade de prestação de serviços ou trabalho a terceiros também cresce entre as cooperativas (14\%), embora seja mais característica nas sociedades mercantis (21\%) e reparte-se igualmente, com percentuais menores (6\%), entre os grupos informais e as associações.

Os dados relacionados à atividade econômica principal dos EES suscitam um aspecto de interesse, no tocante à função preponderante da renda obtida pelos empreendimentos ${ }^{9}$. Os EES representam a fonte primordial de renda dos sócios, principalmente quando sua atividade econômica é a prestação de serviços ou trabalho a terceiros (66\%); a seguir, quando se dedicam à comercialização (50\%) e, por fim, quando sua atividade coletiva principal é a produção (46\%). A forma de organização também interfere no papel que os EES cumprem para seus membros. De forma sintética, os dados demonstram que as empresas mercantis e as cooperativas se identificam com a finalidade de gerar a renda primordial dos sócios, especialmente nos EES de prestação de serviços ou trabalho a terceiros, quando essa característica é mais acentuada (79\%). Entre os grupos informais, o objetivo de gerar uma renda complementar prevalece, chegando a seu máximo (53\%) entre os EES informais de produção. Esses EES também se destacam na função de 
completar rendimentos de aposentadorias ou pensões, ficando acima das demais formas de organização nesse quesito. As associações ficam divididas, servindo a múltiplos objetivos.

Quanto às motivações que levaram à criação dos EES, as cooperativas estão mais vinculadas a princípios de autogestão e a objetivos de trabalho e formação profissional. As associações ficam em posição intermédia, destacando-se no quesito de busca de financiamentos e apoios. Os grupos informais se distanciam dessa perspectiva e respondem, com maior frequência, à busca de uma fonte complementar de renda ou de alternativas ao desemprego. De modo geral, uma síntese comparativa entre as principais formas de organização dos EES, com ênfase nas motivações iniciais que levaram à sua criação e com algumas variáveis relacionadas, revela o seguinte:

- Grupos informais: denotam uma situação de precariedade econômica relacionada ao desemprego e à insuficiência de renda, com menor incidência em objetivos de financiamento ou de ação reativa provocada por políticas públicas. Predominam EES urbanos e de produção.

- Associações: relacionam-se a várias motivações, entre elas o desenvolvimento comunitário e, mais frequentemente, estimulantes externos, a exemplo de políticas de apoio, financiamento, assistência social ou outras. São os EES com maior ocorrência no meio rural.

- Cooperativas: respondem a motivações variadas, principalmente a obtenção de ganhos mais elevados e o desenvolvimento de empresa econômica de propriedade dos sócios. Em segundo lugar, como alternativa de qualificação, atuação profissional, produção ecológica ou como via de recuperação de empresas privadas falidas, através da autogestão.

As cooperativas são EES em geral mais bem estruturados, com indicadores consistentes tanto em relação a estratégias de mercado como a participação em redes econômicas (36\% delas participam, contra 16,5\% dos demais EES), quanto a resultados, como a geração de excedentes (47\% versus $38 \%$ ), em paralelo a requisitos de gestão democrática, como a realização periódica de assembleia (ou reunião geral) dos associados (92\% versus $84 \%$ ), ou a existência de conselho fiscal (68\% versus 46\%). Além disso, constituem o principal modelo e, no Brasil, a alternativa jurídica de organização de empresas econômicas a partir da livre associação e da igualdade societária entre seus membros. No entanto, correspondem a menos de 
$10 \%$ dos EES, o que remete a conhecidas razões e a permanentes debates quanto aos óbices para a formalização dos negócios informais (Chen, 2012) e à desconformidade do marco legal existente em relação às características e aos propósitos da economia solidária (Gaiger, 2015).

Convém, ademais, atentar para o fato de que os empreendimentos informais não são caóticos ou anárquicos, pois dispõem de lógicas intrínsecas e de meios de regulação próprios (Schoofs, 2015). O mesmo aplica-se à figura predominante das associações: um formato incompleto para preencher todas as necessidades de uma empresa econômica, mas menos oneroso e sobretudo mais flexível para viabilizar determinadas atividades, adaptando-se à natureza cambiante e às vezes transitória dos arranjos socioprodutivos da economia popular. A economia solidária traz à baila não tanto a questão da informalidade em si, com seus traços limitantes e suas conotações negativas, mas o universo da semiformalidade, no qual o informal e o formal se entrelaçam, criando um espectro contínuo, um padrão misto estrutural persistente, que não deveria ser entendido como

resultado somente de um processo monolítico de ordem econômica, mas antes o resultado de um processo de codeterminações entre economia, história e cultura (Nogueira, 2018: 90).

Essas diversas comparações entre os EES demonstram que suas características confluem ou divergem parcialmente, sem que haja uma linha nítida de diferenciação a partir de uma única ou de poucas variáveis. Assim, distinguir grupos de EES a partir dos dados do Sies requer análises multivariadas e testes sucessivos, até que se identifiquem fatores discriminantes que delimitem agrupamentos significativamente homogêneos e coerentes. Seguindo esse método, com base nos dados do segundo mapeamento e tendo como fator de agregação selecionado a finalidade principal que os EES cumprem para seus membros, pode-se distinguir cinco tipos característicos:

- EES de provimento de bens, serviços e desenvolvimento comunitário, cuja finalidade principal consiste em aportar bens, serviços e outros benefícios sociais em vista do bem-estar de seus membros - como crédito pessoal, itens de consumo doméstico, serviços socioculturais e educativos - ou fomentar o desenvolvimento associativo e comunitário local.

- EES de apoio à atividade produtiva dos sócios, cuja função mais importante consiste em aportar serviços, recursos e benefícios direcionados às atividades econômicas - individuais ou familiares - de seus 
integrantes, em itens como troca de produtos, comercialização, uso coletivo de equipamentos ou da infraestrutura produtiva.

- EES de trabalho e geração de renda primordial para os sócios, cujo objetivo consiste em produzir bens, em comercializar a produção dos membros ou prestar serviços, de modo a garantir a ocupação e a fonte de ingresso mais importante dos mesmos.

- EES de complementação de trabalho e renda, voltados a atividades similares ao tipo anterior, oferecendo desta vez ocupação e fontes de renda complementares para indivíduos cuja remuneração principal vincula-se a outra atividade econômica ou provém de rendimentos independentes do trabalho.

- EES de trabalho com remuneração insuficiente dos sócios, com atividades semelhantes aos tipos acima mencionados, todavia sem gerar renda adequadamente, seja por não propiciarem trabalho aos sócios de acordo com suas necessidades, seja pelos baixos níveis de remuneração oferecidos.

Os motivos de criação desse último tipo podem ser econômicos e prementes, como aquele de recuperar empresas privadas falidas, por via da sua apropriação e gestão pelos trabalhadores; ou sociais e um tanto difusos, como o de fortalecer os vínculos e a cultura de grupos étnicos, fato especialmente relacionado à presença de povos e comunidades tradicionais na economia solidária. A atividade econômica, nesses casos, funciona como um motivador ou um esteio de atividades de natureza precipuamente sociocultural. As relações entre essas diversas esferas são cambiantes e, no mais das vezes, tais fronteiras são permeáveis ou mesmo intangíveis.

\section{A evolução dos empreendimentos econômicos solidários}

Análises mais detalhadas poderiam indicar outras características predominantes em cada uma dessas tipificações, suas proporções e eventuais subtipos, além de apontar pistas quanto ao processo pelos quais os diferentes empreendimentos moldaram-se ao longo do tempo. Com respeito à formação histórica da economia solidária, no entanto, conviria termos em vista inicialmente alguns aspectos gerais.

Os dados do Sies registram EES criados antes de 1950, ainda ativos na data do mapeamento, embora sejam escassa minoria aqueles que persistiram por tantas 
GRÁFICO 1

PeRCENTUAL ACUMULAdO DE EMPREENDIMENTOS

ECONÔMICOS SOLIDÁRIOS CRIADOS POR PERÍODOS DE TEMPO ATÉ 2010

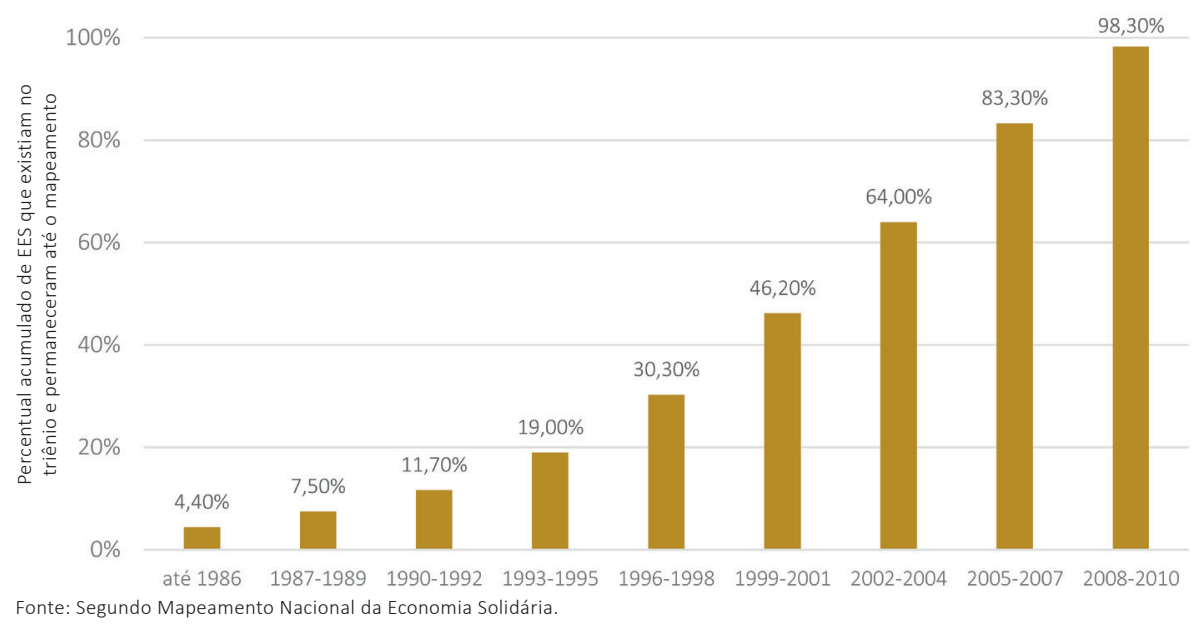

10. O exame de variáveis relacionadas à categoria dos agricultores familiares chama atenção sobretudo para a Região Nordeste. Além de ser a região mais populosa no tocante aos EES mapeados, iniciou o movimento ascensional de EES já a partir dos anos 1970, com nítida aceleração no primeiro triênio da década seguinte, sobretudo sob a forma de associações rurais. décadas e que foram identificados durante a coleta de dados. Nos cerca de 40 anos seguintes - de 1951 até 1989 -, foram criados 7,3\% dos EES, datando da década seguinte - de 1990 até 1999 -, 27\% deles. Do ano 2000 até 2009, surgiram $60,8 \%$ dos EES constantes do segundo mapeamento. Esse movimento ascendente (retratado no Gráfico 1) não reflete o total de EES existentes em épocas passadas, mas sim o total de EES já criados que continuaram existindo até o ano da coleta de informações, entre 2010 e 2013. Por conseguinte, em tempos idos o número de iniciativas similares aos EES deve ter sido bastante superior, como indicam estudos sobre a história do associativismo e do cooperativismo (Schneider \& Lauschner, 1979; Pinho, 1982; Culti, 2008). Nessa perspectiva, a economia solidária corresponderia não a um fenômeno intrinsecamente novo, mas a uma nova geração de iniciativas sociais e econômicas com base na livre adesão e na paridade entre seus integrantes.

Ao examinarmos algumas variáveis dos EES criados até 1989, percebemos que as associações predominam no período que antecedeu o grande surto de EES dos anos 1990 (Gráfico 2), bem como EES com atuação no espaço rural. Assim, não é surpreendente que a categoria social preponderante nessas iniciativas seja a de agricultores familiares. A presença de EES formados por agricultores já se fazia notar nos anos 1970, mas disparou à frente na década seguinte e se manteve na dianteira até os dias atuais ${ }^{10}$.Por quais razões essa categoria social foi a pioneira, já que tantas outras se mobilizaram contra a carestia, em prol de uma elevação dos 
GRÁFICO 2

CRIAÇÃO DOS EMPREENDIMENTOS

ECONÔMICOS SOLIDÁRIOS SEGUNDO A FORMA DE ORGANIZAÇÃO

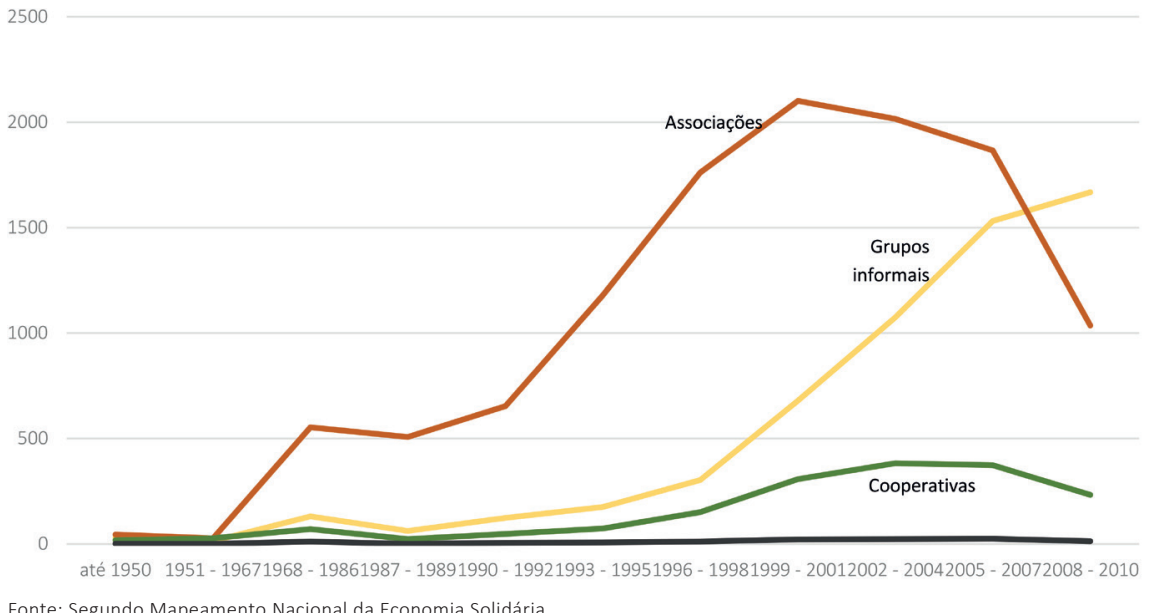

Fonte: Segundo Mapeamento Nacional da Economia Solidária.

salários e outras reivindicações, no contexto das lutas democráticas e de renascimento da sociedade civil na década de 1980? Dentre as possíveis explicações, valeria destacar um elemento que, do ponto de vista da racionalidade da economia solidária, deve ter deixado os agricultores familiares em vantagem: o modo de produção familiar - como também algumas modalidades de economia popular urbana - por sua própria natureza é coletivo ou semicoletivo, no âmbito do núcleo familiar e da comunidade circundante. Práticas de ajuda mútua são costumeiras, alimentam a noção de um projeto coletivo comum e provocam distanciamento do mundo urbano e moderno, com seus modelos culturais e sua mentalidade utilitarista. Sobre isto discorreram diferentes trabalhos clássicos (Candido, 1975) e autores de referência na atualidade (Wanderley, 2014).

Há então uma compatibilidade entre a conduta econômica habitual dos agricultores familiares e o desenvolvimento de estratégias coletivas mais amplas e permanentes (Sabourin, 1999). Essas se viabilizam por meio de organizações específicas que encontram suporte nas estruturas familiares e vicinais e, ao mesmo tempo, as induzem a uma transformação gradativa da lógica estritamente calcada no grupo familiar e no costume, a um processo de adesão premeditada, com inclinação preferencial ao estabelecimento de relações simétricas entre membros da organização. Os dados do Sies que acabamos de mencionar apontam assim para o interesse de se investigar esses temas com diferentes aproximações empíricas, o que permitiria discernir mais amplamente o papel das raízes populares nas dinâmicas 
intrínsecas aos EES, além de dar o justo valor a experiências sociais ainda pouco estudadas e conhecidas.

Uma segunda categoria numericamente significativa na economia solidária é a dos artesãos. Ao computar os dados nacionais, os EES formados principalmente por pessoas com essa ocupação alcançam 17,9\%. Com eles, vamos em direção ao universo urbano, no qual estão concentrados $79 \%$ dos EES desse ramo. Os EES de artesãos são em média mais recentes do que aqueles de agricultores, ainda assim começaram a sobressair-se no início dos anos 1980 e sua curva ascende sensivelmente na década posterior: a presença dos EES de artesãos cresce continuamente desde 1993, alcançando 34\% nos EES criados entre 2011 e 2013, anos de coleta do segundo mapeamento. Trata-se de uma tendência posterior àquela dos EES de agricultores familiares, que também se delineou progressivamente.

Um terceiro segmento de interesse - menos por sua magnitude e mais por suas características peculiares, mais homogêneas - é aquele dos catadores de material reciclável. Compreendem $3,1 \%$ dos EES mapeados e são eminentemente urbanos (92\%), atuando na comercialização (2/3) e na produção (1/3). Compreendem principalmente grupos informais (40\%), mas também se apresentam como associações e cooperativas. À semelhança dos EES de artesãos, sua presença é rarefeita até 1993, quando passa a crescer continuamente, disparando no último triênio anterior ao segundo mapeamento.

O exame comparativo dessas três categorias de EES sinaliza uma gradativa confluência de dinâmicas econômicas, de trabalho e de organização social e política por parte de trabalhadores rurais e urbanos. Uma análise em paralelo dos cinco tipos de EES apresentados na seção anterior também revela que alguns precederam temporalmente outros. EES de provimento de serviços, bens e desenvolvimento comunitário remontam a décadas atrás e mantêm uma presença discreta, mas constante, até o início dos anos 1990, quando se multiplicaram com maior velocidade. EES de apoio à atividade produtiva dos sócios, globalmente mais numerosos, começam a destacar-se um pouco depois, nos anos 1980, subindo e mantendo-se na dianteira até o triênio 2002-2004, quando os EES voltados à geração de trabalho e renda passam a rivalizar em números.

É interessante considerar algumas modulações: os EES de trabalho e geração de renda primordial para os sócios engatinhavam nos anos 1980 e vão exibindo um movimento ascendente, cada vez mais acelerado, até meados dos anos 2000; os EES de complementação de trabalho e renda mostram curva similar, porém mais oscilante, que sobrepuja os demais tipos no final do período; já os EES de 
trabalho com remuneração insuficiente dos sócios aparecem desde os anos 1970, acompanhando o ritmo dos últimos dois tipos citados, com cifras menores no último período, às vésperas do mapeamento. Esse quinto tipo não constitui simplesmente uma variante formada por EES mais jovens ou frágeis momentaneamente, que evoluiriam com o tempo para organizações capazes de gerar renda para seus membros. Mais do que uma questão de etapas, se trata de padrões de EES diferentes e concomitantes. E como a insuficiência de postos de trabalho e de renda, que caracteriza esse último tipo de EES, não leva à sua desativação sistemática, é plausível que outras finalidades e motivações sejam tão ou mais fundamentais, o que deveria ser levado em conta na avaliação da eficiência dessas iniciativas em cumprirem seu papel, sem atribuirmos prerrogativas especiais aos fins econômicos.

Essas constatações deixam em xeque uma visão corrente que interpreta genericamente a economia solidária como uma resposta ao desemprego: elas sugerem uma multiplicidade de circunstâncias favoráveis à revitalização e à expansão de organizações populares de índole associativa. Por sinal, a conjuntura econômica e de emprego dos anos 2000, auge de surgimento dos EES, não foi particularmente negativa para os trabalhadores. Vários indicadores, como a taxa de desemprego, o poder de compra do salário mínimo e o Coeficiente de Gini apresentaram um comportamento positivo do ponto de vista das oportunidades e da distribuição de renda. Ao mesmo tempo, os 23\% de EES criados até 1999 passaram a 41\%, a contar do ano 2000, concentrando-se em áreas urbanas, mais sensíveis às oscilações do mercado de trabalho. Isto conduz a uma tese da teoria econômica de que se torna mais viável e racional fazer escolhas não convencionais diante de um quadro de crescentes opções e de reiterados apoios (Kalecki, 1983). Como a criação e implementação de um EES é uma operação nada trivial (França, 2008), incrementos relativos na segurança econômica dos trabalhadores, somados a instrumentos e estímulos dos programas de apoio à economia solidária, teriam feito a diferença. Programas de redistribuição de renda, como o Bolsa Família, partem aliás dessa premissa: não é por falta de renda mínima, mas sim pela existência dela que os trabalhadores empobrecidos podem sentir-se capazes de enveredar por novos caminhos e persistir em sua concretização; nesse caso, fazendo e sustentando uma aposta na economia solidária (Kuyven, 2016).

A racionalidade em questão não opera num vazio cultural e à revelia de qualquer lastro de experiência, nisso mostrando-se aquém e além de comportamentos utilitaristas, cujas premissas teóricas já foram objeto de severas críticas (Wacquant \& Calhoun, 1991). Provavelmente por isso é que se possa explicar por que os EES juridicamente formalizados como associações são proporcionalmente mais comuns 
11. A propósito, voltando ao segmento de EES dedicados à produção artesanal, 104.278 sócios e sócias trabalhavam nessas atividades "e, desses, aproximadamente $4 / 5(78,1 \%)$ eram mulheres" (Dieese, 2017: 11) até 1999 e menos frequentes no período posterior, ciclo esse que coincide com o auge do crescimento da economia solidária. Embora a formalização das associações seja mais simples e ágil em comparação com as cooperativas e, ademais, possa ser instrumentalizada para fins clientelistas e eleitorais, induzindo à celeridade em sua criação, as associações requerem um agrupamento social prévio, razoavelmente consistente e provido de algum nível de articulação entre seus membros, para perseverarem no tempo. Desse ponto de vista, faz sentido a supremacia de associações entre EES que supõem maior continuidade dos laços comunitários, portanto mais antigos, nos quais a estrutura associativa funciona como anteparo para diferentes atividades de natureza econômica, social e cultural.

A informalidade, por sua vez, condiz com a espontaneidade inicial dos EES, caracterizando assim grupos recentes e menores, com número insuficiente de membros para legalizarem-se como cooperativas ou, mais fundamentalmente, sem um nível de coesão social ou de viabilização dos negócios que justifique bancar o ônus da formalização. Por isso, são mais frequentes no período posterior a 2000. Na conjuntura econômica mais favorável desse período, a profusão de grupos informais não representaria um aprofundamento da precarização, mas uma busca de novas oportunidades de ocupação e renda, supondo então disposição e disponibilidade para agir nessa direção. A economia solidária não visa apenas a renda, mas o ambiente cooperativo e de valorização mútua que, nos grupos informais, diz respeito em particular às mulheres, cuja média de participantes por EES é de 12,5 nesse segmento, contra 7,1 no caso dos homens ${ }^{11}$.

Se mudanças conjunturais funcionaram como estimulantes para a criação de EES, é compreensível que seu quadro social e sua escala de operações sejam inicialmente modestos. Mais adiante, quando as dificuldades iniciais são vencidas, pode fazer sentido agregar novos membros, contanto que tais escolhas considerem o volume da atividade econômica e o seu potencial de crescimento. A esse respeito, as características gerais dos EES, mesmo daqueles tipos direcionados à geração de trabalho e renda, não parecem congruentes com uma perspectiva de crescimento quantitativo, o que de resto sucede com as empresas no Brasil, cujo perfil predominante é de pequeno porte, em média inferior àquele dos EES (Gaiger, 2011). No contexto da economia solidária, um quadro social reduzido pode refletir-se em vida associativa mais intensa, já que os membros são em geral instados a envolver-se na vida cotidiana do EES. O mesmo ocorre quando a iniciativa está em seus primeiros passos e deslanchou pouco antes, sem dispor ainda de rotinas que dispensem contínuas discussões e ajustes. Inovações sociais como essas cobram participação intensa dos agentes envolvidos para se viabilizarem e se propagarem (Ferrarini, 2016). 


\section{Sentidos da economia solidária}

O sentido da economia solidária pode ser avaliado desde várias perspectivas, a exemplo de sua relação com mobilizações e formas de organização anteriores de trabalhadores rurais e urbanos, a contar das lutas operárias do século XIX (Singer, 1999), ou considerando suas incidências atuais sobre o movimento cooperativista (Stahl \& Schneider, 2013; Gaiger, 2013). Pode-se também investigar suas especificidades diante da organização capitalista do trabalho e da produção (Santos, 2002), ponderando-se a respeito de sua força de impulsão no rumo de sociedades pós-capitalistas (Schmidt \& Novaes, 2013). De um modo ou de outro, busca-se nesses casos inquirir sobre o significado histórico da economia solidária. Nessa tarefa, dados sistemáticos e abrangentes sobre o perfil dos EES e sobre seus integrantes não deveriam ser desconsiderados, uma vez que suas características variam e não se prestam a generalizações a partir de casos específicos.

Foi nesses termos que antes identificamos algumas raízes da economia solidária e alguns motivos da ascensão dos EES nos últimos 20 anos. Essa perspectiva de análise converge com a ideia de que essa expansão recente marcaria a ressurgência de visões de mundo embaladas por valores e experiências de luta e de organização, motivando a defesa de sistemas de vida e a resistência contra a expropriação e a indignidade (Singer, 1999). Estudos sobre essas questões indicam que a resolução de necessidades prementes - como trabalho e renda -, bem como a expectativa de contar com algum amparo diante de infortúnios teria motivado indivíduos e coletividades a buscarem alternativas; para tanto, a correrem riscos, a apostarem em laços de confiança, mantendo-se ou ingressando em propostas inabituais - mas não de todo estranhas - como a economia solidária. Assim, deram novo vigor à solidariedade (Bertucci \& Silva, 2003) e à vida associativa (Pinto, 2006). Dos canaviais do Nordeste (Kleiman, 2008) ao coração das metrópoles do Sudeste (Dallari, 2012), essas iniciativas reafirmariam uma tradição mutualista cujos pioneiros, em seu tempo, reagiram não à terceira e atual onda de mercantilização, mas à primeira (Petitclerc, 2007).

Desse ponto de vista, os sentidos da economia solidária deveriam ser contabilizados igualmente - senão principalmente - a partir das respostas que ela oferece a anseios de seus protagonistas diretos. Não apenas, ou antes de tudo, quanto a trazer soluções a necessidades prementes e inadiáveis, mas sim no tocante à atratividade da economia solidária por veicular e dar materialidade a valores e expectativas primordiais, de uma "vida boa" indissociável de uma "vida livre", na semântica de Amartya Sen (Sen, 2000; Fröhlich, 2013). Em outras palavras, no momento de tais escolhas uma dialética se instaura entre necessidades e aspi- 
12. A pergunta, de resposta múltipla, foi aplicada de forma similar no segundo mapeamento (sendo respondida pelo informante escolhido pelo EES) e na pesquisa amostral de sócios e sócias (sorteados entre os membros dos EES, por sua vez escolhidos por amostragem aleatória com base na lista dos EES previamente mapeados). rações. Por serem ambas constructos socioculturais internalizados e modelados pela subjetividade individual, pode-se considerá-las, até certo ponto, intercambiáveis. Mas se por necessidades podemos entender o que instiga os indivíduos a uma ação imediata, devolvendo-os à quietude e a certa passividade, uma vez satisfeitas as aspirações evocariam o que mais profundamente tais indivíduos acalentam, criando expectativas que tendem a retroalimentar-se a cada degrau galgado em sua realização. As aspirações impulsionam-nos em um ciclo ascendente que desperta novas esperanças e, com elas, novas aspirações.

Objetivos alcançados calam mais fundo e provavelmente são mais lembrados quando se relacionam às aspirações. Seria então pertinente estimar os sentidos da economia solidária a partir da avaliação de seus protagonistas diretos quanto ao que buscaram e ao que lograram realizar. Não obstante a padronização das respostas, típica da coleta de dados por questionário, acarrete perda de matizes e mesmo de informações, os dados do Sies oferecem algumas pistas a esse respeito.

Ao serem questionados sobre as principais conquistas obtidas pelos EES, as respostas de seus integrantes remetem a aspectos relacionais como a integração do grupo ou coletivo. Esse item encabeça a lista, secundado por aspectos econômicos de renda e demais ganhos, por sua vez seguidos de uma série de aspectos sociais e políticos: a autogestão e o exercício da democracia, as conquistas para a comunidade local e o comprometimento social dos sócios ${ }^{12}$. O segundo item, relativo a retornos econômicos, é mais frequentemente mencionado nos EES dedicados ao trabalho e à garantia da renda principal dos sócios, seguindo-se a eles os EES de complementação de renda. A autogestão e a democracia também aparecem nesses EES, mas ganham realce em um subgrupo menor de EES que geram renda direta e também apoiam a atividade produtiva dos sócios, caso peculiar de várias associações e cooperativas de recicladores, dentre outros. Esse último subgrupo enfatiza a integração coletiva e o comprometimento social dos integrantes dos EES. Já as conquistas para a comunidade são mais valorizadas pelos EES cuja atividade principal é o consumo de bens e serviços e o desenvolvimento comunitário.

Os dados do mapeamento também trazem os principais desafios dos EES. Apareceram, em primeiro lugar, aspectos econômicos, de renda adequada para os sócios e de viabilização econômica dos EES; a seguir, aspectos sociais e políticos, internos e externos, como manter a união do grupo ou do coletivo, efetivar a participação e a autogestão, promover a articulação com outros EES e com o movimento de economia solidária. As questões de renda adequada e de viabilidade econômica são apontadas sobretudo pelos EES de trabalho e geração de renda, com ênfase ligeiramente maior quando enfrentam dificuldades para remunerar 
os sócios ou quando proporcionam complementação de renda. Por sua vez, os EES de consumo de bens e serviços e de desenvolvimento comunitário salientam o desafio de alcançar a conscientização e a politização dos sócios, além de maior consciência ambiental.

Em linhas gerais, nota-se uma correlação positiva entre a finalidade principal dos EES e suas conquistas mais salientes, na visão dos informantes. O mesmo alinhamento se repete entre a finalidade primordial dos EES e os pontos destacados como desafios principais ${ }^{13}$. Ao considerar que existe campo aberto para avanços e melhorias em várias direções, faz sentido que as finalidades relacionadas à razão de ser primordial dos EES despertem maior interesse de seus integrantes e criem maiores expectativas quanto à realização.

A tendência dessa população é de manter o mesmo nível de atividade nos EES (opção de 41\%) ou de incrementá-la (46\%). Concomitantemente, a participação nos EES induz a envolvimentos mais frequentes em redes, fóruns e organizações sociais e comunitárias, cogitando-se mesmo uma relação biunívoca em alguns casos, como sugere o fato de que, quanto mais antiga a data de ingresso nos EES, maior a taxa de sindicalização (chegando a $72 \%$, entre os ingressantes anteriores a 1980). Esse ativismo econômico, social e político, foi registrado em ambos os mapeamentos. No segundo, o total de EES que declararam participar de movimentos sociais e populares chegou a 58\% (com destaque ao movimento sindical e às lutas pela terra ou pela agricultura familiar), a $46 \%$ no caso de ações sociais ou comunitárias (destaque para as questões relacionadas ao meio ambiente e à educação) e a $40 \%$ no tocante a redes de articulação ou representação (destaques para as redes e estruturas de economia solidária e aos conselhos ou fóruns de políticas públicas).

De volta às conquistas e aos desafios declinados mais vezes, observa-se que podem ser imputados, em alguns casos, a motivações por ganhos e benefícios individualizáveis, embora seja inegável a valorização das relações sociais e da experiência coletiva propiciada pelos EES.

A relevância de uns e outros - de ganhos individuais e coletivos - cresce por se tratar de uma população majoritariamente de baixa renda, sujeita às consequências dessa condição e de traços a ela associados como pretexto de discriminação, a exemplo da cor ou raça: a população branca, de 47,6\% conforme o Censo Demográfico de 2010, decresce para 37\% entre os sócios e as sócias dos EES, ao passo que aquela de pretos eleva-se de $7,8 \%$ para $15 \%{ }^{14}$. Não obstante estarem à contracorrente, esses protagonistas tomam vários rumos e se envolvem em di-
13. As questões relativas às conquistas e desafios dos EES, constantes de um bloco à parte de percepções subjetivas nos instrumentos de coleta, não participaram da construção da tipologia de EES, sob pena de redundância e de nos conduzirem a tautologias.

14. A população indígena, minoritária, também aumenta proporcionalmente: de $0,4 \%$ no Brasil, para $1 \%$ nos EES (dados do Censo referentes a pessoas com cinco anos ou mais: <https:// sidra.ibge.gov.br/ tabela/1379>). 
FIGURA 1

PRINCIPAIS ATIVIDADES DOS EMPREENDIMENTOS

ECONÔMICOS SOLIDÁRIOS DE TIPO 1

FOCOS DE ATUAÇÃO DOS EMPREENDIMENTOS ECONÔMICOS SOLIDÁRIOS

DE PROVIMENTO DE SERVIÇOS, BENS E DESENVOLVIMENTO COMUNITÁRIO

\begin{tabular}{|c|c|c|c|}
\hline Finanças & & Serviços sociais & \\
\hline $\begin{array}{c}\text { Crédito } \\
\text { Conta pessoal }\end{array}$ & & \multirow{5}{*}{$\begin{array}{c}\text { Água } \\
\text { Poços, cisternas, adutoras } \\
\text { Cursos, formação } \\
\text { Creche } \\
\text { Saúde } \\
\text { Transporte } \\
\text { Artes } \\
\text { Música } \\
\text { Festas } \\
\text { Esportes }\end{array}$} & \multirow{3}{*}{$\begin{array}{l}\text { Desenvolvimento } \\
\text { associativo }\end{array}$} \\
\hline Cartão & Consumo & & \\
\hline Repasse & Hortas comunitárias & & \\
\hline $\begin{array}{l}\text { Pagamentos } \\
\text { Benefícios } \\
\text { Pronaf }\end{array}$ & $\begin{array}{l}\text { Criação de animais } \\
\text { Artigos de uso doméstico } \\
\text { Alimentação }\end{array}$ & & \multirow{3}{*}{$\begin{array}{l}\text { Projetos coletivos } \\
\text { Sede social } \\
\text { Equipamentos } \\
\text { Móveis } \\
\text { Espaço de reuniões } \\
\text { Rádio comunitária } \\
\text { Internet }\end{array}$} \\
\hline & & & \\
\hline & & & \\
\hline
\end{tabular}

Fonte: elaboração dos autores

versas atividades (ilustradas na Figura 1) com os focos de atuação de EES voltados ao provimento de serviços e bens ou ao desenvolvimento comunitário. Aspectos econômicos e sociais, individuais e coletivos, mostram-se inseparáveis.

Essas constatações remetem à índole e à lógica peculiar que dinamizariam os EES: assegurar a produção de bens ou a oferta de serviços, viabilizando-as num ambiente de economia de mercado, a partir do trabalho associado, de princípios de autogestão e do emprego em comum de meios de produção. Ao retraduzir em categorias de análise, os EES funcionariam de acordo com uma racionalidade empreendedora e também solidária, cuja sinergia e complementaridade seria de interesse averiguar. Uma das alternativas para explorar a questão a partir dos dados do Sies é a construção de coeficientes que agrupem indicadores relacionados a características e práticas dos EES registradas pelo mapeamento, em quesitos de empreendedorismo e solidarismo. Para observar esse método, um estudo selecionou dez indicadores para cada coeficiente, gerando assim escalas de pontuação

15. Uma demonstração de método encontrase em Kuyven \& Kappes (2013). Ver, igualmente, Gaiger et alii, 2014.

16. Detalhes sobre essa métrica e exemplos de sua aplicação podem ser encontrados em Kuyven (2010). de 1 a 10, cuja soma totalizaria 20 pontos no caso teórico em que os EES satisfizessem todos os critérios ${ }^{15}$.

Ao verificar a existência de uma relação linear entre os dois coeficientes, identificou-se uma tendência geral positiva, em paralelo a casos de ausência de correlação. A tendência de relação linear foi confirmada pelo Coeficiente de Correlação Linear de Pearson, que acusou valores positivos, ainda que brandos ${ }^{16}$. Um elemento tangível associado a essa correlação diz respeito ao volume de faturamento dos EES: em todas as categorias de EES, quanto mais elevado é o faturamento, mais alta é a pontuação nos dois coeficientes. O fato poderia ser lógico do ponto 
de vista do empreendedorismo, embora não se trate aqui do conceito convencional de mera eficiência econômica (Gaiger, 2008), mas não seria presumível em relação ao solidarismo, a menos que essa dimensão das práticas dos EES seja de fato - como então somos levados a presumir - uma mola impulsionadora de bons resultados econômicos.

Um ponto de interesse em desenvolver medidas demonstrativas como essa reside no fato de que permitem uma avaliação comparativa entre os EES no tocante a diversos aspectos, incluindo sua possível racionalidade intrínseca. Assim, pôde-se constatar que alguns grupos específicos se destacam por seu bom desempenho em solidarismo e empreendedorismo: cooperativas, EES de catadores de material reciclável, EES com atuação simultaneamente urbana e rural ou, ainda, EES cuja finalidade é gerar renda - tanto principal como complementar - aos sócios. Outra análise focalizou o perfil dos EES com pontuação mínima de 18 pontos, isto é, perfilamento situado no topo da escala. Nesse grupo restrito predominam cooperativas, principalmente de produção, com destaque à metalurgia, seguida pela agricultura e prestação de serviços por profissionais de nível superior. Com uma exceção, os EES nesse caso tinham ao redor de 15 anos de funcionamento, de 8 a 703 sócios e uma composição de sexo refletindo a divisão sexual do trabalho, ora com predomínio de mulheres, ora de homens, conforme o setor de atividade econômica. Para 100\% deles, o resultado econômico dos EES garantia a principal fonte de renda dos sócios.

Tem-se aqui um segmento modelar, no qual o êxito econômico não se opõe ao desenvolvimento de práticas solidárias: na conjunção entre gestão participativa e eficiência, ou no equacionamento entre viabilidade e equidade, residiria a sua racionalidade. Ainda que a materialização desta seja variável e sujeita a reveses, o fato de apresentar-se como uma tendência tangível - e não apenas como possibilidade virtual - traz argumentos convincentes e retroalimenta as idealizações e ações dos atores engajados na economia solidária. Corrobora um entendimento predominante a seu respeito, que a considera como alternativa econômica, no terreno das práticas e, em perspectiva teleológica, como fundamento de um sistema econômico alternativo (Coraggio, 2016).

\section{Considerações finais}

Visão prospectiva e adesão a projetos são inerentes à defesa e à promoção de ideias, programas e experiências. Há poucos meses das eleições de 2018, no entanto, a ação política vê-se ainda em um estado de perplexidade e de incertezas quanto a formas efetivas de mobilização; no caso da economia solidária, ade- 
mais, pode-se constatar sinais claros de desmonte das políticas governamentais e dos espaços de participação na esfera pública que se estruturaram nos últimos 15 anos. Há um esfriamento das ações, uma compreensível perda de ritmo nos debates e menor assertividade nas formulações sobre as perspectivas futuras da economia solidária. Todavia, convém lembrar que suas iniciativas pioneiras se depararam, nos anos 1980, com uma correlação de forças desfavorável no plano nacional e na esmagadora maioria dos governos estaduais e municipais.

Assim, mais do que uma desabalada carreira de salvação diante da crise, a conjuntura atual pode representar uma oportunidade de reflexão, avaliação e balanço da trajetória percorrida até agora pelos EES e pelas demais organizações atuantes no campo da economia solidária.

Nesse sentido, importa caracterizar de forma ampla o universo em questão e identificar as tendências. Anos atrás, este mesmo periódico científico publicou um artigo que chamava a atenção para o valioso cabedal de informações disponibilizados pelo Sies, referindo-se à época aos dados do primeiro mapeamento nacional, concluído em 2007 (Gaiger, 2012). Transcorridos agora outros seis anos do final do segundo mapeamento, constata-se que tais informações, somadas aos dados da pesquisa amostral sobre sócios e sócias dos EES, permanecem inexploradas, salvo algumas exceções (Silva \& Kappes, 2016; Dieese, 2015, 2017). Ora, para qualquer questão de pesquisa que implique observar a regularidade e contabilizar a recorrência de fatos singulares - sejam comportamentos ou características de uma dada população - bases de informação representativas são indispensáveis. Além disso, a existência de dois levantamentos similares faculta análises diacrônicas e retrospectivas, uma vez que cada mapeamento em verdade armazena registros de iniciativas localizadas e até certo ponto disseminadas em conjunturas históricas encadeadas ao longo do tempo. Várias histórias de associativismo popular deixaram suas pegadas no Sies. Ademais, pode-se trabalhar com subconjuntos de dados ou utilizar o Sies como base para amostragens específicas ou com vistas à seleção de casos para estudos qualitativos.

Não seria demais acrescentar que, afora as variáveis em sua forma original, as bases de dados do Sies facultam tanto comparações com outras bases, como aquelas do IBGE (com variáveis similares sobre a população nacional), quanto a criação de indicadores de acordo com os tópicos de interesse. Tome-se como exemplo os modelos de autogestão ou o impacto do protagonismo das mulheres sobre as formas de gestão e a própria natureza dos EES, uma das questões de grande relevância, como já se demonstrou em estudos sobre dados do primeiro mapeamento nacional (Schneider, 2010). 


\section{Referências}

BERTUCCI, Ademar; SILVA, Marinho (Orgs.). Vinte anos de economia popular solidária. Brasília: Cáritas Brasileira, 2003.

CANDIDO, Antonio. Os parceiros do rio Bonito. 3. ed. São Paulo: Duas Cidades, 1975.

CHEN, Martha. The informal economy: definitions, theories and policies. Wiego Working Paper, n. 1, 2012.

CORAGGIO, José (Org.). Economía social y solidaria en movimento. Los Polvorines (ARG): Universidad Nacional de General Sarmiento, 2016.

CULTI, Maria. O cooperativismo popular no Brasil: importância e representatividade, 2008. Disponível em: <https://pt.scribd.com/document/11776068/O-Cooperativismo-Popular-No-Brasil-Importancia-e-Representatividade>. Consultado em: 16 Maio 2018.

DALLARI, Mônica. Cooperativa dos vendedores autônomos do Parque Ibirapuera. O passo a passo de uma história de sucesso. Rio de Janeiro: Elsevier, 2012.

DEPARTAMENTO INTERSINDICAL DE ESTATÍSTICA E ESTUDOS SOCIOECONÔMICOS (DIEESE). A comercialização na economia solidária em empreendimentos urbanos de produção artesanal lideradas por mulheres. Cadernos de Debates do Observatório da Economia Solidária e do Cooperativismo, n. 2, 2017.

. A informalidade na economia solidária. Cadernos de Debates do Observatório da Economia Solidária e do Cooperativismo, n. 1, 2015.

FERRARINI, Adriane. O ethos da inovação social: implicações ético-políticas para o estudo de práticas produzidas em diferentes ambientes. Contemporânea, v. 6, n. 2, p. 447-466, 2016.

FRANÇA, Bárbara et alii. Guia de economia solidária ou porque não organizar cooperativas para populações carentes. Niterói (RJ): Universidade Federal Fluminense, 2008.

FRÖHLICH, Sandro. Reflexões sobre a liberdade: uma perspectiva a partir de Amartya Sen. Controvérsia, v. 9, n. 1, p. 23-31, 2013.

GAIGER, Luiz. Collaborative research between civil society, state and the academia. Lesson from the Brazilian Mapping of the Solidarity Economy. In: BOUCHARD, M.; ROUSSELIÈRE, D. (Eds.). The weight of the social economy. An international perspective, p. 205-230. Brussels (BEL): Peter Lang, 2015. 
- Conhecer globalmente: um desafio inadiável dos estudos sobre a economia solidária. Revista Otra Economía, v. 8, n. 14, p. 101-113, 2014.

- A economia solidária e a revitalização do paradigma cooperativo. Revista Brasileira de Ciências Sociais, v. 28, n. 82, p. 211-228, 2013.

- Por um olhar inverso: prismas e questões de pesquisa sobre a economia solidária. Sociedade e Estado, v. 27, n. 2, p. 313-335, 2012.

- Relações entre equidade e viabilidade nos empreendimentos solidários. Lua Nova, n. 83, p. 79-109, 2011.

—. A dimensão empreendedora da economia solidária. Notas para um debate necessário. Revista Otra Economía, v. 2, n. 3, p. 58-72, 2008.

- (Org.). Sentidos e experiências da economia solidária no Brasil. Porto Alegre: Editora UFRGS, 2004.

GAIGER, Luiz; CORRÊA, Andressa. A história e os sentidos do empreendedorismo solidário. Revista Otra Economía, v. 4, n. 7, p. 153-176, 2010.

GAIGER, Luiz et alii. A economia solidária no Brasil: uma análise de dados nacionais. São Leopoldo (RS): Oikos, 2014.

KALECKI, Michal. Teoria da dinâmica econômica: ensaio sobre as mudanças cíclicas e a longo prazo da economia capitalista. São Paulo: Abril Cultural, 1983.

KLEIMAN, Fernando. Lições de Catende. A construção de uma autogestão em Pernambuco. São Paulo: Annablume, 2008.

KUYVEN, Patrícia. Efeitos da economia solidária sobre a geração de renda e a redução da pobreza: um estudo de dados nacionais. Tese (Doutorado em Ciências Sociais) - Programa de Pós-graduação em Ciências Sociais, Universidade do Vale do Rio dos Sinos, São Leopoldo, Rio Grande do Sul, 2016.

- Métodos estatísticos aplicados ao processo decisório. São Leopoldo (RS): Unisinos, 2010.

KUYVEN, Patrícia; KAPPES, Sylvio. A relação entre o grau de solidarismo e o índice de sobrevivência de empreendimentos econômicos solidários na região sul do Brasil. VIII Congresso Internacional Rulescoop. São Leopoldo, 2013.

NOGUEIRA, Mauro. Infinitos tons de cinza: entre o formal e o informal, o Brasil se faz no informal. Mercado de Trabalho, n. 64, p. 87-97, 2018. 
PETITCLERC, Martin. "Nous protégeons l'infortune». Les origines populaires de I'Économie Sociale au Québec. Montreal: VLB Éditeur, 2007.

PINHO, Diva. O pensamento cooperativo e o cooperativismo brasileiro. São Paulo: Coopercultura, 1982.

PINTO, João. Economia solidária; de volta à arte da associação. Porto Alegre: Editora UFRGS, 2006.

SABOURIN, Eric. Práticas de reciprocidade e economia de dádiva em comunidades rurais do Nordeste brasileiro. Raízes, v. 18, n. 20, p. 41-49, 1999.

SANTOS, Boaventura (Org.). Produzir para viver; os caminhos da produção não capitalista. Rio de Janeiro: Civilização Brasileira, 2002.

SCHMIDT, Carlos; NOVAES, Henrique (Orgs.). Economia solidária e transformação social: rumo a uma sociedade para além do capital? Porto Alegre: Editora UFRGS, 2013.

SCHNEIDER, José; LAUSCHNER, Roque. Evolução e situação atual do cooperativismo brasileiro. In: O Cooperativismo no Brasil: Enfoques, análises e contribuição. Rio Grande do Sul: Friedrich Neumann e Associação de Orientação às Cooperativas, p. 1-58, 1979.

SCHNEIDER, Élen. As potencialidades da economia solidária na redução das desigualdades de gênero. Protestantismo em Revista, n. 23, p. 11-20, 2010.

SCHOOFS, Steven. Making sense of informal economies in fragile contexts: issues, dilemmas and questions. Conflict research unit policy brief. Clingendael (NED): Netherlands Institute of International Relations, 2015.

SEN, Amartya. Desenvolvimento como liberdade. São Paulo: Companhia das Letras, 2000.

SILVA, Daniel; KAPPES, Sylvio. Economia solidária, informalidade e direitos trabaIhistas. Mercado de Trabalho, n. 61, p. 89-96, 2016.

SILVA, Sandro. Crise de paradigma? A política nacional de Economia Solidária no PPA 2016-2019. Mercado de Trabalho, n. 64, p. 163-172, 2018.

SINGER, Paul. Uma utopia militante. 2. ed. Petrópolis (RJ): Vozes, 1999.

STAHL, Reni; SCHNEIDER, Odelso. As interfaces entre cooperativismo e economia solidária. Ciências Sociais Unisinos, v. 9, n. 2, p. 197-206, 2013. 
WANDERLEY, Maria de Nazareth. O campesinato brasileiro: uma história de resistência. Revista de Economia e Sociologia Rural, v. 52, n. 1, p. 25-44, 2014.

WACQUANT, LoÏc; CALHOUN, Craig. Interesse, racionalidade e cultura. Revista Brasileira de Ciências Sociais, v. 6, n. 15, p. 76-92, 1991.

(c) (9) (9) 